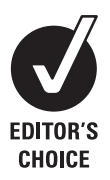

- Additional data

(Supplementary figure 1) are published online only at http:// bjsm.bmj.com/content/vol43/ issue6

${ }^{1}$ Cincinnati Children's Hospital, Cincinnati, Ohio, USA;

${ }^{2}$ University of Pennsylvania,

Philadelphia, Pennsylvania, USA;

${ }^{3}$ The Orthopaedic Center,

Rockville, Maryland, USA

Correspondence to:

T E Hewett, Cincinnati Children's Hospital, USA; tim.hewett@

cchmc.org

Accepted 31 March 2009

Published Online First

15 April 2009

\title{
Video analysis of trunk and knee motion during non- contact anterior cruciate ligament injury in female athletes: lateral trunk and knee abduction motion are combined components of the injury mechanism
}

\author{
T E Hewett,, J S Torg, ${ }^{2}$ B P Boden ${ }^{3}$
}

\begin{abstract}
Background: The combined positioning of the trunk and knee in the coronal and sagittal planes during non-contact anterior cruciate ligament (ACL) injury has not been previously reported.

Hypothesis: During ACL injury female athletes demonstrate greater lateral trunk and knee abduction angles than ACL-injured male athletes and uninjured female athletes.

Design: Cross-section control-cohort design.

Methods: Analyses of still captures from 23 coronal (10 female and 7 male ACL-injured players and 6 female controls) or 28 sagittal plane videos performing similar landing and cutting tasks. Significance was set at $p \leqslant 0.05$.
\end{abstract}

Results: Lateral trunk and knee abduction angles were higher in female compared to male athletes during $\mathrm{ACL}$ injury $(p \leqslant 0.05)$ and trended toward being greater than female controls ( $p=0.16,0.13$, respectively). Female ACL-injured athletes showed less forward trunk lean than female controls (mean (SD) initial contact (IC): $1.6(9.3)^{\circ}$ vs $\left.14.0(7.3)^{\circ}, p \leqslant 0.01\right)$.

Conclusion: Female athletes landed with greater lateral trunk motion and knee abduction during ACL injury than did male athletes or control females during similar landing and cutting tasks.

Clinical relevance: Lateral trunk and knee abduction motion are important components of the ACL injury mechanism in female athletes as observed from video evidence of ACL injury.

Adolescent and mature females who participate in pivoting and jumping sports suffer anterior cruciate ligament (ACL) injuries at a 2-10-fold greater rate than male athletes participating in the same high-risk cutting and landing sports. ${ }^{1-6}$ The combination of this greater susceptibility and a 10-fold increase in the female sports population since the inception of Title IX of the US Education Amendments act of 1972 (now known as the Patsy T Mink Equal Opportunity in Education Act) has resulted in a dramatic increase in the number of ACL injuries in females. ${ }^{5}$ In the USA, 100000 to $250000 \mathrm{ACL}$ injuries occur each year. ${ }^{78}$ The costs exceed US $\$ 650$ million annually in solely female high school and collegiate varsity athletics. ${ }^{9}$ Neuromuscular control deficits at the hip and trunk may contribute to decreased active neuromuscular control of the lower extremity (LE) that may lead to increased knee abduction loads and strain on the knee ligaments. ${ }^{10-13}$ In addition to the costs associated with ACL reconstruction and rehabilitation, there is a strong association between ACL injury and development of posttraumatic knee osteoarthritis, which also occurs with much greater incidence in females than males. ${ }^{14} 15$ It is estimated that between $50 \%$ and $100 \%$ of women with an ACL injury will show significant pain, functional limitations and radiographic signs of knee osteoarthritis within 12 to 20 years of the index injury. ${ }^{14} 16$

Knee abduction loads and neuromuscular control of the trunk both predict ACL injury risk with high sensitivity and specificity in female athletes. Knee abduction load predicted ACL injury risk with $78 \%$ sensitivity and $73 \%$ specificity. ${ }^{12}$ Trunk displacement, and specifically lateral trunk displacement, predicted risk of knee, knee ligament and ACL injuries with high sensitivity and specificity in female, but not male, athletes. ${ }^{17}$ A logistic regression model that incorporated lateral trunk motion predicted ACL injury risk in females with $83 \%$ sensitivity and $76 \%$ specificity, but did not predict knee or ACL injury risk in males. The mechanism of non-contact ACL injury may differ in females and males, especially with respect to the dynamic positioning of the knee, as females demonstrate greater valgus collapse of the lower extremity primarily in the coronal plane. ${ }^{18}$ Most ACL injuries in females occur by non-contact mechanisms during landing, deceleration and lateral pivoting. ${ }^{19}$ The mechanism of non-contact ACL injuries as observed on video has several common components in female athletes: high knee abduction, lateral trunk motion with the body shifted over the injured leg and the plantar surface of the foot fixed flat on the playing surface, displaced away from the centre of mass of the body and low knee flexion. ${ }^{18-21}$ Perturbation of the trunk, game or competitive situation and another player within close proximity are other common components of the mechanism. ${ }^{18} 22$

Trunk motion can influence knee abduction load through mechanical and neuromuscular mechanisms. If the trunk moves laterally, the ground reaction force (GRF) vector may move laterally and have a greater lever arm relative to the knee joint centre. This will directly increase the potential for knee abduction loading, especially if at the same time the magnitude of GRF increases due to unicompartmental (ie, lateral compartment) knee joint loading and/or increased inertial acceleration of the trunk or thigh segments during dynamic 
movement. Knee abduction torque places knee ligaments in the high slope (load) segment of their force-length curve and elicits knee pain in female athletes. ${ }^{23} 24$

The purposes of the present study were to determine the trunk and knee position of female and male athletes at the time of ACL injury, and to compare these results with those of uninjured control athletes. The tested hypothesis was that compared with female control athletes and male subjects, injured female subjects would show greater lateral trunk angles and greater knee abduction angles at landing after a jump, pivoting or after a sharp deceleration manoeuvre.

\section{MATERIALS AND METHODS}

\section{Data collection}

During a 12-year period (1995 to 2007), we requested from physicians, athletic trainers, patients and the National Basketball Association (NBA Entertainment (NBA and Womens NBA (WNBA) games)) videotapes of athletes captured during an ACL injury requiring reconstruction. A total of 70 such videotapes were collected. Our study was exempt from institutional review board approval. Criteria for inclusion of a video in our study were: (1) good quality, with the camera angle approximating a sagittal (lateral) or coronal (anterior or posterior) view of the athlete; (2) visualisation of the foot contacting the ground; (3) unobscured view of the athlete; and (4) no or minimal contact during the athletic manoeuvre. Minimal contact included being touched by an opponent, such as shoulder to shoulder contact during a rebound. Videotapes were excluded if the athlete was being tackled or pushed by an opponent or if there was any direct contact to the knee. For a more detailed account of these methods see Boden et al..$^{22}$

In all, 23 injury videos met the criteria for this study: 10 female and 7 male ACL-injured players and 6 female controls performing similar landing and cutting tasks. We tabulated injury conditions such as type of sport, level of play, game or high-intensity practice situation, level of contact (none or minimal), activity being performed (vertical jump, broad jump, or deceleration), whether the player was on offence or defence, whether the subject was holding a ball and whether another player was in close proximity (being guarded or guarding another athlete).$^{22}$

The same author selected and assessed videotapes of professional and collegiate basketball players (controls) performing similar decelerating or landing manoeuvres during game situations. ${ }^{22}$ Basketball was the sport of choice for the controls because of the availability of high-quality videos from professional and collegiate matches and because of the close proximity of the camera to the athletes. ${ }^{22}$

\section{Video editing and analysis}

The video recordings were edited using Adobe Premiere Pro (V 2.0, Adobe Systems, San Jose, California, USA) and deinterlaced to achieve a $30-\mathrm{Hz}$ (frames/s) effective frame rate via Abode Photoshop (V CS2, Adobe Systems). ${ }^{22}$ Initial contact (IC) with ground was analysed on each video. The trunk and joint kinematic measures were performed from the video sequences using ImageJ software (http://rsb.info.nih.gov/ij/). Joint angles were analysed in five sequential frames (stored as TIFF files) in sagittal or coronal planes, starting with initial ground-foot contact (time 0). Therefore, the time sequences observed were at approximately, initial contact of the foot with the floor and $50 \mathrm{~ms}, 100 \mathrm{~ms}, 150 \mathrm{~ms}$ and $200 \mathrm{~ms}$ post contact. ImageJ was used to measure joint angles after drawing lines based on the landmarks described below. ${ }^{25}{ }^{26}$ All measurements were performed by the same author for consistency.

The trunk position was measured by connecting a line perpendicular to the floor and through the superior tip of the greater trochanter and a line drawn from the superior tip of the greater trochanter to the superior tip of the acromioclavicular joint (fig 1). For the anterior views the trunk lean angle was measured by connecting a line from the centre of the neck at the C7 level to the centre of the symphysis pubis and a line from the centre of the symphysis pubis perpendicular to the ground. For the posterior frames the trunk bend was measured by connecting a line from the centre of C7 to the centre of L4 and a line perpendicular to the ground and intersecting the centre of L4. The anterior and posterior views were analysed together to assess the coronal position. For a more detailed account of these methods see Boden et al. ${ }^{22}$

\section{Statistical analysis}

All angle measurements were imported into Statview V 5.01 (SAS Institute, Cary, North Carolina, USA) for statistical analysis. Repeated measures analysis of variance (ANOVA) with Fisher protected least significant difference (PLSD) post hoc tests were performed to assess if there were statistically significant differences between female subjects and controls, and male and female ACL-injured subjects. Significance was set at $p \leqslant 0.05$. Intraclass coefficients (ICCs) were calculated to assess the reproducibility of the angle measurements at each video frame sequence at three different times. The single rater repeated the measured videotape frames of 4 angles in a total of 10 subjects (2 angles/6 subjects; 2 angles/4 subjects). The estimated ICCs ranged from 0.32-0.99, with 18 of the 20 coefficients greater than $0.95 .^{22}$

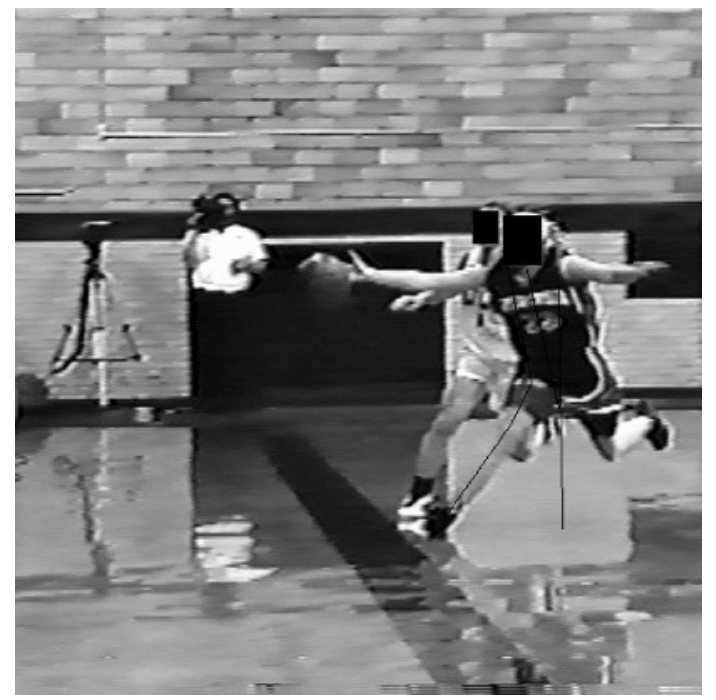

Figure 1 Still image of a female anterior cruciate ligament (ACL)injured subject during injury (front player, no. 22) relative to a control player (behind her), demonstrating the association between lateral trunk motion and medial knee collapse in the injured subject, but not the control player (obscured view, not analysed). This is frame 1 (initial foot contact with ground) of the subject (no. 22) landing and shows the calculated angles and the combined lateral trunk motion and knee abduction. 


\section{RESULTS}

\section{Lateral trunk angle}

Figure 1 shows an ACL-injured subject demonstrating combined lateral trunk motion and knee abduction during ACL injury. The mean lateral trunk angle relative to the vertical was higher in female athletes during ACL injury than in male players during ACL injury ( $p=0.02$; fig 2$)$ and trended toward being greater than female controls $(p=0.16)$ performing similar landing and cutting tasks across the five repeated measures frames assessed, or approximately $200 \mathrm{~ms}$ of landing (fig 3). These differences were significant between female and male ACL-injured subjects at IC (mean (SD) $11.1(2)^{\circ}$ vs $-5.5(9.5)^{\circ}$, $\mathrm{p}=0.04$ ) and trended toward being greater than female controls performing similar landing and cutting tasks (IC: $11.1(1.2)^{\circ}$ vs $\left.4.2(9.6)^{\circ}, p=0.29\right)$. The mean anterior-posterior trunk angle relative to vertical was not different in female athletes during ACL injury than in males (IC: $1.6(9.3)^{\circ}$ vs -6.7 (8.6) $\mathrm{p}=0.20)$. In addition, female ACL-injured athletes demonstrated less forward trunk lean than female controls (IC: 1.6 $(9.3)^{\circ}$ vs $\left.14.0(7.3)^{\circ}, p=0.005\right)$.

\section{Knee abduction angle}

Female ACL-injured subjects demonstrated significantly increased knee abduction during landing compared to male ACL-injured subjects and showed a trend toward more knee abduction than female controls $(p \leqslant 0.05$; fig 4$)$. After initial contact, the knee abduction moment remained relatively unchanged in the controls, but the female ACL-injured subjects showed progressively more knee abduction with each consecutive sequence (fig 4). The mean differences between subjects and controls for the third through fifth frames were significant $(p \leqslant 0.05)$. No significant differences were observed in knee flexion angle between subjects and controls across the five repeated measure frames. There were no significant differences observed in knee flexion between either female and male ACLinjured subjects or between female ACL-injured subjects and female controls. ${ }^{22}$

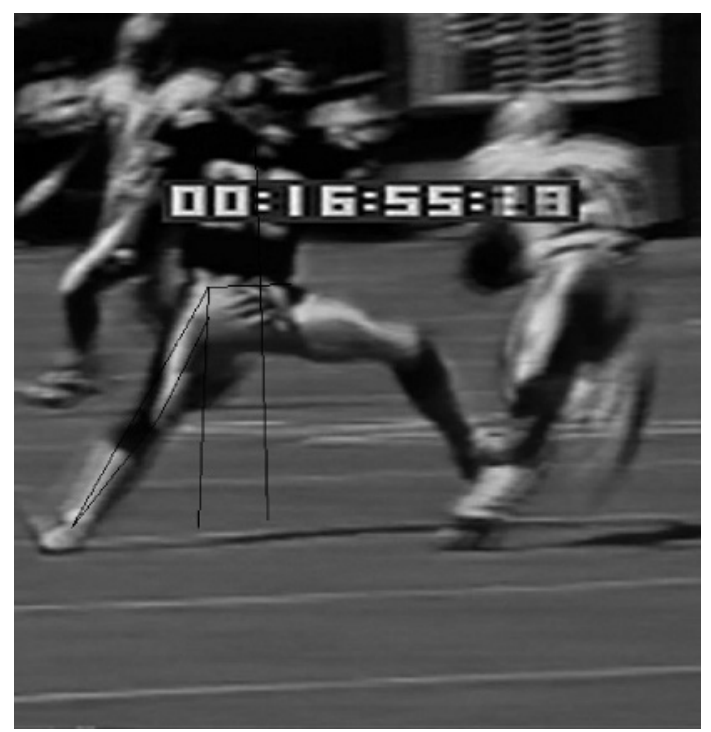

Figure 2 Still image with coronal angles a male subject demonstrating the absence of an association between lateral trunk motion and medial knee collapse during anterior cruciate ligament ( $A C L$ ) injury.

\section{DISCUSSION}

We accepted the alternative hypothesis for the present study, namely that injured female subjects would show greater lateral trunk and greater knee abduction motion at landing compared to male injured subjects and uninjured female control athletes, since injured female subjects were observed to demonstrate greater lateral trunk and greater knee abduction angles than male subjects and female controls during landing injury (see figs 3 and 4 and Supplementary material). To our knowledge, there is no similar published data on trunk position in either descriptive or analytic studies of ACL injury. Trunk stability is related to the ability of the hip to control the trunk in response to forces generated from distal body segments as well as from unexpected perturbations. ${ }^{17}{ }^{27}$ Deficits in neuromuscular control of the trunk during cutting and landing may lead to uncontrolled lateral trunk motion that may increase knee abduction motion and torque through mechanical (lateral GRF motion) and neuromuscular (increased hip adductor torque) mechanisms. ${ }^{11} 12$ Insufficient neuromuscular control of the trunk may increase strain on the ACL and lead to injury via either one or both of these mechanisms. ${ }^{10-13}$

Neuromuscular control of the hip is required to stabilise the trunk and pelvis. An external hip abduction moment created by the GRF moving lateral to the centre of the femoral head is counterbalanced internally by hip adductor torque. For example, during normal gait, with the lateral trunk motion that occurs in early stance, the hip adductors are activated in order to adduct the pelvis and move the trunk toward the midline. ${ }^{28}$ Females activate the hip musculature differently than males in response to sudden loading. ${ }^{29}$ Women adduct the hip more than men during low and high intensity activities. They begin descent in a more abducted knee position and remain in a more abducted alignment relative to men throughout a squat motion or during landing. ${ }^{30} 31$ Females also demonstrate more hip adduction than males during cutting. ${ }^{32}{ }^{33}$ Increased hip adduction during dynamic motion and decreased hip muscle abductor strength and recruitment can increase knee load and injury risk. Ipsilateral trunk lean may be a sign of weak hip abductors as it moves the centre of mass closer to the stance limb to reduce demand on the weak abductors. ${ }^{27}{ }^{34}$ During single leg landing and cutting, the entire body mass must be balanced over one lower extremity. Because the trunk comprises greater than half of the body's mass, lateral trunk motion increases GRF and knee abduction load. ${ }^{34}$

Deficits in neuromuscular control of the trunk may contribute to lower extremity joint instability and injury. ${ }^{35}$ This may be due to a resulting decrease in active joint stiffness in women than men. ${ }^{36-38}$ Landing and cutting require high levels of neuromuscular control to maintain stability and performance. ${ }^{39}{ }^{40}$ Dynamic stability of the knee is dependent upon accurate sensory input and appropriate motor responses to rapid changes in body position during cutting and landing. ${ }^{12} 35$ Neuromuscular control of the hip, trunk and knee is based on feedback control. The position and load of each segment is used to modify the descending movement commands. ${ }^{41}$ Impaired control of the hip and trunk can increase lower extremity injury. For example, abdominal muscle fatigue contributes to hamstring injuries. ${ }^{42}$ Subjects with ankle sprains had a delay in onset of gluteus maximus and medius activation. ${ }^{43}$ Female, but not male, athletes who suffered ankle injury had greater body sway prior to injury than uninjured controls. ${ }^{44}$

Movement biomechanics and lower extremity strength can be altered in females with neuromuscular training. ${ }^{45}$ Neuromuscular power can increase within 6 weeks of training 


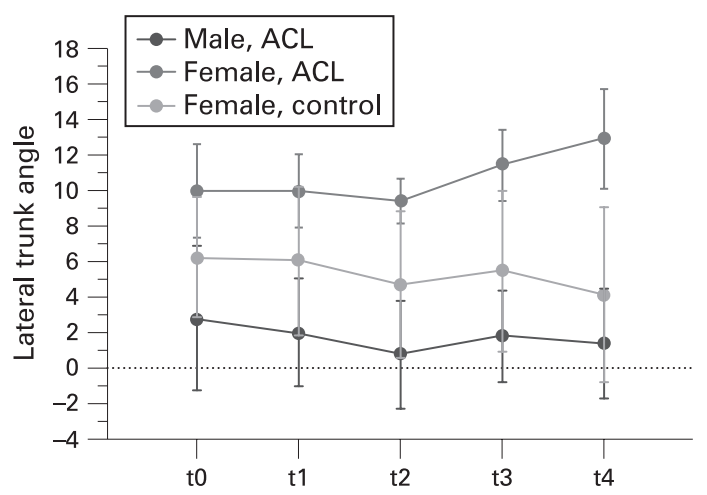

Figure 3 Coronal plane trunk angles (mean (standard error of the mean $(\mathrm{SEM})))$ in female and male anterior cruciate ligament (ACL)-injured subjects and female controls.

and may result in decreases in peak impact forces and knee abduction moments. ${ }^{45-48}$ Observed changes in females may be greater than in males as their baseline neuromuscular performance levels are lower. ${ }^{49}$ If neuromuscular training can decrease ACL injury risk, it is likely that the mechanisms underlying increased risk are neuromuscular in nature. ${ }^{50} \mathrm{ACL}$ injury risk may be reduced in trained females during landing and cutting. ${ }^{51}$ Elite female athletes show reductions in ACL injuries with neuromuscular training. ${ }^{52}$ These prospective studies indicate that neuromuscular training has the potential to decrease ACL injury rates in females.

Neuromuscular control of the trunk and lower extremity can be improved with neuromuscular training, ${ }^{12} 45475354$ which may increase coronal plane trunk and hip control in females. ${ }^{45} 4955$ For example, during a drop-jump, a two-footed plyometric activity, post training results showed that lower extremity valgus was reduced at the hip. Conversely, during a single-leg landing task, the most significant modifications may occur at the knee. ${ }^{47}$ Therefore, the effects of training in the coronal plane are likely to be movement task specific. ${ }^{47}$ Increased coronal plane control at the hip and trunk may be necessary to reduce ACL injury risk. ${ }^{56-58}$ lower extremity coronal joint motions and torques linked to increased ACL injury risk are often correlated, indicating that control of knee load may require synergistic and antagonistic contribution from the trunk, hip and knee. ${ }^{12}$ Perturbation-enhanced training may increase trunk control and decrease knee abduction load in females.

The current video evidence of ACL injuries shows that the female trunk usually moves lateral to the ACL-injured limb as the knee abducts (fig 1 and Supplementary material), while this is not a common observation in males (fig 2). Trunk position and knee load may be mechanically linked, as lateral positioning of the trunk can create abduction loads at the knee. ${ }^{28}$ In the coronal plane, applying static equilibrium mechanics and neglecting the inertia of the body segments between hip and ground, if the GRF passes lateral to the centre of the head of the femur, an external hip abduction torque results. ${ }^{28} 60$ Interestingly, even alteration of arm position relative to the centreline of the body can increase the external knee abduction load by $29 \%$ to $60 \%{ }^{56}$ At the low knee flexion angles that are present during ACL injuries, the ACL, rather than the MCL, can be the primary restraint to knee abduction loads. ${ }^{56162}$ Knee abduction load and ACL injury may be outcomes that result from an unstable, collapsing lower extremity column under axial load, caused by the GRF passing through the lateral knee compartment.

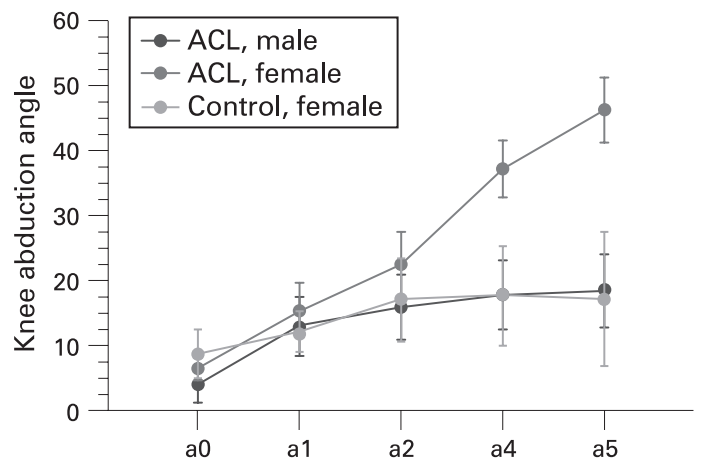

Figure 4 Coronal plane knee abduction angles (mean (standard error of the mean (SEM))) in female and male anterior cruciate ligament (ACL)injured subjects and female controls.

Females tend to utilise greater coronal plane control rather than a sagittal plane control strategy for the lower extremity. ${ }^{6-66}$ They tend to utilise a "hip strategy" for single leg control and balance during landing and cutting. ${ }^{306}$ For example, coronal plane excursions are greater and more rapid at the hip and knee during walking in females. ${ }^{59}$ The knee functions optimally as a sagittal plane hinge, not a coronal plane hinge or ball and socket joint, as the large muscles of the lower extremity that limit coronal plane trunk, hip and knee motion or torque absorb and dissipate force most effectively and efficiently in the sagittal, rather than coronal plane. ${ }^{68}$

A coronal plane, quadriceps dominant (ie, flat footed and knee abducted) landing strategy likely leads to higher ground reaction and ACL injury risk in female athletes. Females that land with knee abduction are at increased risk for ACL injury. ${ }^{72}$ A combined flat foot and abducted knee position likely result in high axial ground reaction forces in the lateral compartment of the knee joint. With combined knee abduction and flat foot, the ground reaction force cannot be effectively absorbed by the prime movers of the lower extremity. ${ }^{69}$ If there is an axial ground reaction force on the lateral joint, this may lead to internal rotation of the tibia on the femur, which increases strain on the ACL. ${ }^{13}$

Previous studies of ACL injuries based on videotape analysis have relied on visual inspection to determine joint positions. ${ }^{1970} 71$ Visual inspection has poor accuracy and precision for joint angle measurement. ${ }^{72}$ In a study assessing the accuracy of the visual inspection technique, the mean error for knee flexion was 19 degrees, while the standard deviation between the observers for hip flexion was 18 degrees on average. ${ }^{72} \mathrm{We}$ used a digital measuring tool to define joint position more accurately and more quantitative.

The present observations show that lateral trunk rotation to the ipsilateral side likely increases valgus, axial and/or compressive forces on the lateral side of the knee joint, lowering the threshold for ACL injury. These findings agree with those of Krosshaug et al that female athletes showed greater knee abduction position ("valgus collapse") after and possibly during ACL injury than do their male counterparts. There was also a trend in our female subjects toward more knee abduction after landing than was shown by male subjects; this finding may indicate that there is more inherent knee abduction in females during landing than in males, which concurs with the data of Hewett et al. ${ }^{12}$ Hewett et al ${ }^{12}$ showed that a landing pattern with knee abduction is a risk for ACL injury, which may explain the higher incidence of non-contact ACL injury in women than in men. It is possible that with knee abduction, the axial forces 
are greater on the lateral side of the knee than on the medial side, further enhancing the lateral compressive forces and allowing for a greater internal rotation component to the injury. In addition, with knee abduction, the ligaments on the lateral side of the knee are relaxed while the medial side tightens, allowing the lateral side to shift anteriorly and rotate. ${ }^{69}$ Matsumoto showed that, with a valgus torque, the axis of the pivot shift is located at the medial collateral ligament. ${ }^{69}$ If the medial collateral ligament is taut, the movement of the medial side of the tibia is limited. ${ }^{69}$ In contrast, there is an axial or compressive force on the lateral joint. The combination of medial and lateral compartment forces may lead to internal rotation of the tibia on the femur, which can dramatically increase the strain on the ACL. ${ }^{13}$

Increased hip abductor muscle recruitment and strength likely has a direct effect on the knee abduction loading of the ACL during cutting and landing. Though ACL injuries likely occur too quickly (likely under $100 \mathrm{~ms}$ ) for reflexive muscular activation (greater than $100 \mathrm{~ms}$ ), athletes can adopt preparatory muscle recruitment and movement patterns that reduce the probability of injuries caused by unexpected perturbations. ${ }^{24} 7374$ We hypothesise that decreased neuromuscular control of the trunk leads to increased joint load (knee abduction moment) via lateral motion of the GRF and results in increased ACL injury risk in female athletes (figs 1 and 3 ). In addition, the sagittal trunk observations were that the injured female subjects had less trunk flexion than female controls. This may place their trunk in line with the leg to increase valgus and/or the axial forces. However, decreased flexion at trunk did not appear to alter flexion at other lower extremity joints.

\section{Potential limitations}

There were several limitations to our study. We had a relatively small sample size of videotapes, which were collected as a convenience sample, for each camera angle. These videotapes may not be representative of all non-contact ACL injury mechanisms, but the observed motions likely represent some of the most common non-contact or minimal contact mechanisms of ACL injury. We were unable to determine the exact moment at which the ACL injury occurred. However, by measuring several consecutive frames in which the knee was deforming abnormally (compared to the knee of a control) and the athlete fell to the ground and grabbed the knee, it is likely that the injury occurred within the five measured frames. In addition, although such conditions cannot be matched perfectly in different groups, even in a laboratory setting, the descriptive findings for our subjects and controls were fairly evenly matched. Because measuring knee abduction in the coronal plane does not account for rotation of the leg (internal rotation of the femur and external rotation of the tibia), our coronal knee abduction angles may not be pure knee abduction but, rather, a combination of knee abduction, internal rotation of the femur and external rotation of the tibia. This problem may be compounded by the fact that the body may be rotating but the camera is being held still. Unfortunately, with a twodimensional analysis, we were unable to separate these components of motion. Future studies analysing ACL injury videotapes where the injury was captured from more than one camera angle may be able to provide a more accurate threedimensional assessment of the various components. ${ }^{75}$

There were also several potential limitations in our technical analysis: possible difficulties with identifying anatomic landmarks in clothed individuals with no markers, camera angle variability that may not have captured all individuals in a perfect sagittal or coronal plane, possible microsecond differences in the timing of the first sequence picked as the foot touched the ground to the point of injury and the limitations of two-dimensional analysis. However, this computerised technique of angle measurements is a considerable improvement over previous descriptive studies based purely on visual estimates of joint position. Despite these limitations, to our knowledge ours is the first study to analyse trunk position in videotaped ACL injuries with a group of controls for comparison. Kinematic analysis with two or more synchronised camera views would provide more accurate data and data not yet recorded in the literature. $^{75}$

\section{Summary and conclusions}

This study may advance the understanding of the mechanisms and prevention of ACL injuries in female athletes, who are at a 2-10-fold increased risk of ACL injury than males. Our objectives are to determine the mechanisms by which female athletes become more susceptible to ACL injury and to optimise the effectiveness of interventions designed to prevent ACL injuries. Specifically, this study was directed towards understanding and answering the question of whether increased lateral sway of the trunk underlies increased abduction loading of the knee joint during ACL injury in female athletes. The present evidence supports this theory (see red arrows in Supplementary material). This information may enhance the efficacy of ACL prevention programs. Prophylactic intervention for ACL injury could prevent a significant percentage of the 100000 to 250000 injuries that occur each year in the USA. ${ }^{7}$ Reduction of female injury rates from fivefold greater to equal male injury rates would potentially allow females annually to continue the health benefits of sports participation and avoid the long-term complications of osteoarthritis, which occurs with a 10-fold to 100-fold greater incidence in ACL-injured than in uninjured athletes. ${ }^{14} 16$

Funding: This work was supported in part by NIH/NIAMS grants R01 AR049735, R01 AR05563 and R01 AR056259 (TEH).

Competing interests: None.

Ethics approval: Ethics approval was obtained.

\section{REFERENCES}

1. Arendt E, Dick R. Knee injury patterns among men and women in collegiate basketball and soccer. NCAA data and review of literature. Am J Sports Med 1995;23:694-701.

2. Chandy TA, Grana WA. Secondary school athletic injury in boys and girls: a threeyear comparison. Phys Sportsmed 1985;13:106-11.

3. Deitch JR, Starkey C, Walters SL, et al. Injury risk in professional basketball players: a comparison of Women's National Basketball Association and National Basketball Association athletes. Am J Sports Med 2006;34:1077-83.

4. Malone TR, Hardaker WT, Garrett WE, et al. Relationship of gender to anterior cruciate ligament injuries in intercollegiate basketball players. J South Orthop Assoc 1993;2:36-9.

5. NCAA. NCAA injury surveillance system summary. Indianapolis, Indiana, USA: National Collegiate Athletic Association, 2002.

6. Zelisko JA, Noble HB, Porter M. A comparison of men's and women's professional basketball injuries. Am J Sports Med 1982;10:297-9.

7. Hewett TE, Lindenfeld TN, Riccobene JV, et al. The effect of neuromuscular training on the incidence of knee injury in female athletes. A prospective study. Am J Sports Med 1999;27:699-706.

8. Toth AP, Cordasco FA. Anterior cruciate ligament injuries in the female athlete. J Gend Specif Med 2001;4:25-34.

9. Myer GD, Ford KR, Hewett TE. Rationale and clinical techniques for anterior cruciate ligament injury prevention among female athletes. J Athl Train 2004;39:352-64.

10. Bendjaballah MZ, Shirazi-Adl A, Zukor DJ. Finite element analysis of human knee joint in varus-valgus. Clin Biomech (Bristol, Avon) 1997:12:139-48.

11. Hewett TE, Myer GD, Ford KR. Reducing knee and anterior cruciate ligament injuries among female athletes: a systematic review of neuromuscular training interventions. J Knee Surg 2005;18:82-8. 
12. Hewett TE, Myer GD, Ford KR, et al. Biomechanical measures of neuromuscular control and valgus loading of the knee predict anterior cruciate ligament injury risk in female athletes: a prospective study. Am J Sports Med 2005;33:492-501.

13. Markolf KL, Burchfield DM, Shapiro MM, et al. Combined knee loading states that generate high anterior cruciate ligament forces. J Orthop Res 1995;13:930-5.

14. Lohmander LS, Ostenberg A, Englund $M$, et al. High prevalence of knee osteoarthritis, pain, and functional limitations in female soccer players twelve years after anterior cruciate ligament injury. Arthritis Rheum 2004;50:3145-52.

15. von Porat A, Roos EM, Roos H. High prevalence of osteoarthritis 14 years after an anterior cruciate ligament tear in male soccer players: a study of radiographic and patient relevant outcomes. Ann Rheum Dis 2004;63:269-73.

16. Myklebust G, Bahr R. Return to play guidelines after anterior cruciate ligament surgery. Br J Sports Med 2005;39:127-31.

17. Zazulak BT, Hewett TE, Reeves NP, et al. Deficits in neuromuscular control of the trunk predict knee injury risk: a prospective biomechanical-epidemiological study. Am J Sports Med 2007;35:1123-5.

18. Krosshaug T, Nakamae A, Boden BP, et al. Mechanisms of anterior cruciate ligament injury in basketball: video analysis of 39 cases. Am J Sports Med 2007 Mar;35:359-67.

19. Olsen $\mathbf{O E}$, Myklebust G, Engebretsen L, et al. Injury mechanisms for anterior cruciate ligament injuries in team handball: a systematic video analysis. Am J Sports Med 2004;32:1002-12.

20. Griffin LY. The Henning program. In: Griffin LY, ed. Prevention of noncontact ACL injuries. Vol 1. Rosemont, Illinois, USA: American Academy of Orthopaedic Surgeons, 2001:93-96.

21. Ireland ML. The female ACL: why is it more prone to injury? Orthop Clin North Am 2002;33:637-51.

22. Boden BP, Torg JT, Knowles SB, et al. Video analysis of anterior cruciate ligament injury: abnormalities in hip and ankle kinematics. Am J Sports Med 2009;37:252-9.

23. Markolf KL, Graff-Redford A, Amstutz HC. In vivo knee stability: a quantitative assessment using an instrumented clinical testing apparatus. J Bone Joint Surg 1978;60A:664-74.

24. Pope $\mathbf{M}$, Johnson R, Brown D. The role of the musculature in injuries to the medial collateral ligament. J Bone Joint Surg 1979;61-A:398-402.

25. Abramoff MD, Magalhaes PJ, Ram SJ. Imaging processing with ImageJ. Biophotonics Int 2004;11:36-42.

26. Rasband WS. Image porcessing and anlaysis. Bethesda, Maryland, USA: US National Institutes of Health, 2007.

27. MacKinnon CD, Winter DA. Control of whole body balance in the frontal plane during human walking. J Biomech 1993;26:633-44.

28. Winter DA. Biomechanics and motor control of human movement. 3rd edn. New York, USA: John Wiley \& Sons, 2005

29. Granata KP, Orishimo KF, Sanford AH. Trunk muscle coactivation in preparation for sudden load. J Electromyogr Kinesiol 2001;11:247-54.

30. Hewett TE, Ford KR, Myer GD, et al. Gender differences in hip adduction motion and torque during a single leg agility maneuver. J Orthop Res 2006;24:416-21.

31. Zeller BL, McCrory JL, Kibler WB, et al. Differences in kinematics and electromyographic activity between men and women during the single-legged squat. Am J Sports Med 2003;31:449-56.

32. McLean SG, Su A, van den Bogert AJ. Development and validation of a 3-d model to predict knee joint loading during dynamic movement. J Biol Chem 2003;125:864-74.

33. Pollard CD, Davis IM, Hamill J. Influence of gender on hip and knee mechanics during a randomly cued cutting maneuver. Clin Biomech 2004;19:1022-31.

34. Perry J. Gait analysis: normal and pathological function. Thorofare, New Jersey, USA: SLACK, 1992

35. Hewett TE, Paterno MV, Myer GD. Strategies for enhancing proprioception and neuromuscular control of the knee. Clin Orthop 2002;402:76-94.

36. Hurd WJ, Chmielewski TL, Axe MJ, et al. Differences in normal and perturbed walking kinematics between male and female athletes. Clin Biomech 2004;19:465-72.

37. Wojtys EM, Ashton-Miller JA, Huston LJ. A gender-related difference in the contribution of the knee musculature to sagittal-plane shear stiffness in subjects with similar knee laxity. J Bone Joint Surg Am 2002;84-A:10-16.

38. Wojtys EM, Huston LJ, Schock HJ, et al. Gender differences in muscular protection of the knee in torsion in size-matched athletes. J Bone Joint Surg Am 2003;85-A:782-9.

39. Loram ID, Kelly SM, Lakie M. Human balancing of an inverted pendulum: is sway size controlled by ankle impedance? J Physiol 2001;532:879-91.

40. Loram ID, Lakie M. Human balancing of an inverted pendulum: position control by small, ballistic-like, throw and catch movements. J Physiol 2002;540:1111-24.

41. Gandevia SC, McCloskey DI, Burke D. Kinaesthetic signals and muscle contraction. Trends Neurosci 1992;15:62-5.

42. Devlin L. Recurrent posterior thigh symptoms detrimental to performance in rugby union: predisposing factors. Sports Med 2000;29:273-87.

43. Beckman SM, Buchanan TS. Ankle inversion injury and hypermobility: effect on hip and ankle muscle electromyography onset latency. Arch Phys Med Rehabil 1995;76:1138-43.

44. Beynnon BD, Renstrom PA, Haugh $L$, et al. A prospective, randomized clinical investigation of the treatment of first-time ankle sprains. Am J Sports Med 2006;34:1401-12.
45. Hewett TE, Stroupe AL, Nance TA, et al. Plyometric training in female athletes. Decreased impact forces and increased hamstring torques. Am J Sports Med 1996;24:765-73.

46. Myer GD, Ford KR, Brent JL, et al. Predictors of sprint start speed: the effects of resistive ground based vs inclined treadmill training. J Strength Cond Res 2007:21:491-6.

47. Myer GD, Ford KR, McLean SG, et al. The effects of plyometric versus dynamic stabilization and balance training on lower extremity biomechanics. Am J Sports Med 2006;34:490-8.

48. Myer GD, Ford KR, Palumbo JP, et al. Neuromuscular training improves performance and lower-extremity biomechanics in female athletes. J Strength Cond Res 2005; 19:51-60.

49. Kraemer WJ, Mazzetti SA, Nindl BC, et al. Effect of resistance training on women's strength/power and occupational performances. Med Sci Sports Exerc 2001:33:1011-25

50. Hewett TE, Myer GD, Ford KR. Anterior cruciate ligament injuries in female athletes: part 1, mechanisms and risk factors. Am J Sports Med 2006:34:299-311.

51. Hewett TE, Ford KR, Myer GD. Anterior cruciate ligament injuries in female athletes: part 2, a meta-analysis of neuromuscular interventions aimed at injury prevention. Am J Sports Med 2006:34:490-8.

52. Myklebust G, Engebretsen L, Braekken IH, et al. Prevention of anterior cruciate ligament injuries in female team handball players: a prospective intervention study over three seasons. Clin J Sport Med 2003;13:71-8.

53. Beck JL, Wildermuth BP. The female athlete's knee. Clin Sports Med 1985:4:345-66

54. Huston LJ, Wojtys EM. Neuromuscular performance characteristics in elite female athletes. Am J Sports Med 1996;24:427-36.

55. Tropp H, Odenrick P. Postural control in single-limb stance. J Orthop Res 1988:6:833-9.

56. Chaudhari AM, Andriacchi TP. The mechanical consequences of dynamic frontal limb alignment for non-contact ACL injury. J Biomech 2006;39:330-8.

57. McLean SG, Huang $X$, Su A, et al. Sagittal plane biomechanics cannot injure the ACL during sidestep cutting. Clin Biomech 2004;19:828-38.

58. Padua DA, Marshall SW, Beutler Al, et al. Predictors of knee valgus angle during a jump-landing task. Med Sci Sports Exerc 2005;37:S398.

59. Hurd WJ, Chmielewski TL, Snyder-Mackler L. Perturbation-enhanced neuromuscular training alters muscle activity in female athletes. Knee Surg Sports Traumatol Arthrosc 2006; 14:60-9.

60. Hurwitz DE, Foucher KC, Andriacchi TP. A new parametric approach for modeling hip forces during gait. J Biomech 2003;36:113-19.

61. Andriacchi TP, Natarajan RN, Hurwitz DE. Musculoskeletal dynamics, locomotion, and clinical applications. In: Mow VC, Hayes WC, eds. Basic orthopaedic biomechanics, 2nd edn. Philadelphia, Pennsylvania, USA: Lippincott-Raven, 1997:37-68.

62. Wu G, Siegler S, Allard P, et al. ISB recommendation on definitions of joint coordinate system of various joints for the reporting of human joint motion-part I: ankle, hip, and spine. International Society of Biomechanics. J Biomech 2002;35:543-8.

63. Ford KR, Myer GD, Hewett TE. Valgus knee motion during landing in high school female and male basketball players. Med Sci Sports Exerc 2003;35:1745-50.

64. Ford KR, Myer GD, Toms HE, et al. Gender differences in the kinematics of unanticipated cutting in young athletes. Med Sci Sports 2005:37:124-9.

65. Kernozek TW, Torry MR, H VH, et al. Gender differences in frontal and sagittal plane biomechanics during drop landings. Med Sci Sports Exerc 2005;37:1003-12.

66. McLean SG, Lipfert SW, van den Bogert AJ. Effect of gender and defensive opponent on the biomechanics of sidestep cutting. Med Sci Sports Exerc 2004;36:1008-16.

67. Ford KR, Myer GD, Smith RL, et al. A comparison of dynamic coronal plane excursion between matched male and female athletes when performing single leg landings. Clin Biomech (Bristol, Avon) 2006;21:33-40.

68. Stergiou N, Jensen JL, Bates BT, et al. A dynamical systems investigation of lower extremity coordination during running over obstacles. Clin Biomech (Bristol, Avon) 2001;16:213-21.

69. Matsumoto H. Mechanism of the pivot shift. J Bone Joint Surg 1990;72:816-21.

70. Boden BP, Dean GS, Feagin JA, et al. Mechanisms of anterior cruciate ligament injury. Orthopedics 2000;23:573-8.

71. Teitz CC. Video analysis of ACL injuries. In: Griffin LY, ed. Prevention of noncontact ACL injuries. Vol 1. Rosemont, Illinois, USA: American Academy of Orthopaedic Surgeons, 2001:87-92.

72. Krosshaug T, Nakamae A, Boden B, et al. Estimating 3D joint kinematics from video sequences of running and cutting maneuvers-assessing the accuracy of simple visual inspection. Gait Posture 2007:26:378-85.

73. Cowling EJ, Steele JR, McNair PJ. Effect of verbal instructions on muscle activity and risk of injury to the anterior cruciate ligament during landing. Br J Sports Med 2003;37:1-11.

74. Yasuda K, Erickson AR, Beynnon BD, et al. Dynamic elongation behavior in the medial collateral and anterior cruciate ligaments during lateral impact loading. J Orthop Res 1993;11:190-8.

75. Krosshaug T, Bahr R. A model-based image-matching technique for threedimensional reconstruction of human motion from uncalibrated video sequences. J Biomech 2005;38:919-29. 